\title{
Numerical Study of Periodic Long Wave Run-up on a Rigid Vegetation Sloping Beach
}

\author{
Jun Tang ${ }^{\mathrm{a}, *}$, Yongming Shen ${ }^{\mathrm{a}}$, Derek M Causon ${ }^{\mathrm{b}}$, Ling Qian ${ }^{\mathrm{b}}$, Clive G Mingham ${ }^{\mathrm{b}}$ \\ a State Key laboratory of Coastal and Offshore Engineering, Dalian University of \\ Technology, Dalian 116024, China \\ b Centre for Mathematical Modelling and Flow Analysis, Manchester Metropolitan \\ University, Manchester M1 5GD, UK
}

\begin{abstract}
Coastal vegetation can reduce long wave run-up on beaches and inland propagation distances and thus mitigate these hazards. This paper investigates periodic long wave run-up on coastal rigid vegetation sloping beaches via a numerical study. Rigid vegetation is approximated as rigid sticks, and the numerical model is based on an implementation of Morison's formulation for rigid structures induced inertia and drag stresses in the nonlinear shallow water equations. The numerical model is solved via a finite volume method on a Cartesian cut cell mesh. The accuracy of the numerical model is validated by comparison with experimental results. The model is then applied to simulate various hypothetical cases of long period wave run-up on a sloping vegetated beach with different plant diameters and densities, and incident long waves with different periods. The sensitivity of long wave run-up to plant diameter, stem density and wave period is investigated by comparison of the numerical results for different vegetation characteristics and different wave periods. The numerical results show that rigid vegetation can effectively reduce long wave run-up and that wave run-up is decreased with increase of plant diameter and stem density. Moreover, the attenuation of long periodic wave run-up due to vegetation is sensitive to the variation of the incident wave period, and the attenuation of wave run-up is not increased or decreased monotonically with incident wave period.
\end{abstract}

Key Words: Periodic Long Wave; Rigid Vegetation; Wave Run-up; Nonlinear Shallow Water Equations

\section{Introduction}

As a long wave propagates shoreward it undergoes changes caused by the offshore bathymetry and can increase significantly in height near the shoreline, run-up on the beach and travel inland considerable distances with the potential to cause large

* Corresponding author. Tel: +86-411-84708514.

E-mail: jtang@dlut.edu.cn (Jun Tang). 
property damage including damage to infrastructure and facilities, devastation of coastal ecosystems and settlements, and massive loss of human life. Long wave run-up has been observed to vary significantly depending upon the local bathymetry and vegetation characteristics along the coastline. Vegetation such as mangroves and salt marshes, as well as belts of sea grass and seaweed are being increasingly recognized as important for dissipating wave energy and improving safety in the coastal zone (Tanaka, 2009). Coastal vegetation may not only provide a shield to coastal structures including breakwaters and seawalls but may also reduce wave inundation and run-up. Understanding and predicting a long wave run-up and inland propagation process is an important aspect of the coastal wave mitigation effort. Thus, a study of long wave water propagation through vegetation on a beach is fundamental to an understanding of how long wave run-up may be reduced by planted vegetation along a coastline.

There has been a lot of work done to study the mitigating effects of vegetation on coastal wave run-up using numerical simulations, and different numerical and analytical models have been proposed to relate the interactions between coastal waves and plants to explain the damping effects of vegetation (Kobayashi et al., 1993; Harada and Imamura, 2005; Tanaka et al., 2007; Augustin et al., 2009; Huang et al., 2011; Mei et al., 2011; Tang et al., 2011; Suzuki et al., 2012; Chen and Zhao, 2012; Iimura and Tanaka, 2012; Wu and Marsooli, 2012; Tang et al., 2013; Ma et al., 2013; Maza et al., 2013; Jadhav et al., 2013; Zhang et al., 2013; Tang et al., 2015; Jiang et al., 2015; Liu et al., 2015; Zhu and Chen, 2015; Wang et al., 2015; Guannel et al., 2015; Losada et al., 2016). The often-used numerical models for water wave propagation on vegetation include phase averaged wave models that account for the effects of vegetation in an energy dissipation term and phase-resolved models that account for vegetation resistance as drag and inertial forces. Compared to phase averaged wave models (Suzuki et al., 2012; Chen and Zhao, 2012; Jadhav et al., 2013; Tang et al., 2015; Guannel et al., 2015; Losada et al., 2016), phase-resolved models, such as Boussinesq, shallow water or RANS, use the momentum equations and are capable of directly simulating dynamic wave shape deformations (Kobayashi et al., 1993; Harada and Imamura, 2005; Tanaka et al., 2007; Augustin et al., 2009; Huang et al., 2011; Mei et al., 2011; Iimura and Tanaka, 2012; Wu and Marsooli, 2012; Tang et al., 2013; Ma et al., 2013; Maza et al., 2013; Zhang et al., 2013; Fang et al., 2015; Jiang et al., 2015; Liu et al., 2015; Zhu and Chen, 2015; Wang et al., 2015). Kobayashi et al. (1993) presented an analytical solution showing how a 
monochromatic wave decays exponentially in vegetation based on the vertically two-dimensional continuity and linearized momentum equations for small amplitude waves. Harada and Imamura (2005) proposed a model consisting of a numerical simulation based on the one-dimensional shallow water equations in which the resistance of vegetation was evaluated by drag forces on trees and drag coefficients of pines estimated on the basis of field observations and laboratory experiments. Tanaka et al. (2007) improved the expression of drag force so that the vertical stand characteristics of trees were considered more realistically, and proposed depth-averaged equivalent drag coefficients for various tropical trees on the basis of field investigations in Sri Lanka, Thailand, and Indonesia. Augustin et al. (2009) simulated irregular wave propagation in flexible vegetation in a shallow-water wave basin with the COULWAVE Boussinesq equations including the effects of vegetation. Huang et al. (2011) studied solitary wave interaction with emergent rigid vegetation in a wave flume using the Boussinesq equations with the effects of vegetation. Mei et al. (2011) presented analytical and numerical solutions for long surface waves of small amplitude and attenuation on the macro-scale for different bathymetries and coastal forest configurations. Iimura and Tanaka (2012) studied the effects of tree density distribution on tsunami mitigation using the Boussinesq equations including drag and inertia forces caused by vegetation. Wu and Marsooli (2012) developed a shallow water model that simulated long waves in a vegetation zone under breaking and non-breaking conditions and the numerical results showed that vegetation along a coastal shoreline has a positive benefit in reducing wave run-up on sloping beaches. Tang et al. (2013) developed a model for investigating the effects of damping due to vegetation on solitary wave run-up that was based on the nonlinear shallow water equations and the numerical results showed that vegetation can effectively reduce solitary wave propagation velocity and solitary wave run-up is decreased with increases of plant height in water and also diameter and stem density. Ma et al. (2013) developed a RANS model to investigate wave propagation through a finite patch of vegetation in the surf zone and the numerical results showed that the presence of a finite patch of vegetation may generate strong near-shore currents with an onshore mean flow in the unvegetated zone and an offshore return flow in the vegetated zone. Maza et al. (2013) presented a RANS model for wave and submerged vegetation which couples the flow motion with plant deformation, and velocities inside and outside a flexible vegetation meadow were validated. Zhang et al. (2013) presented a vertical 2-D RANS model for wave propagation through vegetated and non-vegetated 
waters in which the $k-\varepsilon$ model was used for turbulence closure. Liu et al. (2015) developed a mathematical model for small-amplitude periodic waves propagating through an aquatic forest within a finite extent. Zhu and Chen (2015) presented a coupled wave-vegetation model based on the non-hydrostatic WAVE model (NHWAVE) excluding turbulence and diffusion for simulating the interaction between waves and submerged flexible plants. Phan et al. (2015) studied the efficiency of mangrove width to attenuate wave energy using the extended XBeach model in which wave attenuation by vegetation was implemented, and their results show that long waves need more distance for attenuation. Maza et al. (2015) studied the influence of solitary wave steepness, vegetation density and vegetation arrangement on tsunami wave attenuation using a three dimensional numerical approach based on IHFOAM. Van Rooijen et al. (2016) studied the effect of wave-vegetation interaction on wave setup using the extended XBeach model in which wave attenuation by vegetation was implemented, and their results show that the effect of wave-vegetation interaction on wave setup may be relevant for a range of typical coastal geomorphological configurations. These researches have explained the damping effects of vegetation on waves using numerical simulations, and improved our insight into the mitigating effects of coastal vegetation on water wave propagation. However, compared to the progress made on modeling wave propagation on a vegetated plane, wave run-up on a planted sloping beach has been less well studied. Notably, long period wave run-up on a planted sloping beach, and the effects of vegetation characteristics such as vegetation density, diameter on a long periodic wave run-up mitigation effects have been less studied. Moreover, the relationship between the wave period and vegetation mitigation effects on long wave run-up has rarely been studied.

The present paper numerically investigates the effects of damping due to rigid vegetation on long period wave run-up. Rigid vegetation is approximated as rigid sticks and the numerical model is based on an implementation of Morison's formulation (1950) for rigid structures, induced inertia and drag stresses in the nonlinear shallow water equations. The model is solved using a finite volume formulation in conjunction with Cartesian cut cell meshes. The model is firstly tested for solitary wave run-up on a bare sloping beach and long period wave run-up on a partially-vegetated sloping beach to examine the accuracy of the present model. Then, the model is applied to simulate various hypothetical cases of long period wave run-up on a sloping vegetated beach with different plant diameters and densities, and 
incident waves with different periods. The sensitivity of wave run-up to plant diameter and density, as well as incident wave period, is investigated by comparison of the numerical results for different vegetation characteristics and different wave periods.

\section{Numerical Methods}

\subsection{Governing Equations}

Wave propagation and run-up processes in a shallow water zone can be modeled by the nonlinear shallow water equations as wave nonlinear effects are more prominent than dispersion effects in these zones. As a wave approaches the shore line, the wave length becomes shorter and amplitude becomes larger. Therefore, the effects of wave non-linearity become increasingly dominant and frequency dispersion becomes negligible. Thus, the nonlinear shallow water equations may be used for modelling the behavior of waves in these zones. Vegetation attenuation effects on waves can be approximated by including plant induced inertia and drag stresses in the nonlinear shallow water equations in which rigid vegetation is approximated by rigid sticks and the Morison's formulation (1950) for rigid structures induced inertia and drag stresses is implemented. When the attenuation offered by vegetation is considered, the shallow water equations take the following conservative form:

$$
\begin{aligned}
& h_{t}+\nabla \cdot(h \mathbf{V})=0 \\
& (h \mathbf{V})_{t}+h \mathbf{V} \cdot \nabla \mathbf{V}=\mathbf{S}_{\mathrm{b}}+\mathbf{S}_{\mathrm{f}}+\mathbf{S}_{\mathrm{veg}}
\end{aligned}
$$

In the above equations, $h$ is water depth, $\mathbf{V}=(u, v)^{T}$ depth-averaged velocity,

$(,)^{T}$ means the transpose matrix, $\mathbf{s}_{\mathrm{b}}$ accounts for bathymetry bed slope, $\mathbf{s}_{\mathrm{f}}$ for bottom induced friction term and $\mathbf{S}_{\mathrm{veg}}$ for vegetation induced drag term per unit area, and defined as:

$$
\begin{aligned}
& \mathbf{S}_{\mathrm{b}}=\left(-g h \frac{\partial \eta}{\partial x},-g h \frac{\partial \eta}{\partial y}\right)^{T} \\
& \mathbf{S}_{\mathrm{f}}=\left(-\frac{1}{\rho} \tau_{x}^{\mathrm{f}},-\frac{1}{\rho} \tau_{y}^{\mathrm{f}}\right)^{T}
\end{aligned}
$$




$$
\mathbf{S}_{\mathrm{veg}}=\left(-\frac{1}{\rho} \tau_{x}^{\mathrm{veg}},-\frac{1}{\rho} \tau_{y}^{\mathrm{veg}}\right)^{T}
$$

Where $\eta$ is water surface level from a horizontal datum, $g$ the acceleration due to gravity, $\rho$ water density, $\tau_{x}^{\mathrm{f}}$ and $\tau_{y}^{\mathrm{f}}$ are friction forces in $x$ and $y$ directions respectively, defined here as:

$$
\begin{gathered}
\tau_{x}^{\mathrm{f}}=\frac{1}{2} \rho c_{\mathrm{f}} u|\mathbf{V}| \\
\tau_{y}^{\mathrm{f}}=\frac{1}{2} \rho c_{\mathrm{f}} v|\mathbf{V}|
\end{gathered}
$$

$c_{\mathrm{f}}$ bed friction coefficient, $\tau_{x}^{\mathrm{veg}}$ and $\tau_{y}^{\mathrm{veg}}$ are drag and inertia forces on plants in $x$ and $y$ directions respectively. The general rigid plants are usually approximated as rigid sticks with bending effects ignored, and $\tau_{x}^{\mathrm{veg}}$ and $\tau_{y}^{\mathrm{veg}}$ can be defined based on the Morison's equations (1950) for rigid structures as:

$$
\begin{gathered}
\tau_{x}^{\mathrm{veg}}=\frac{1}{2} \rho c_{\mathrm{d}} b_{\mathrm{veg}} h_{\mathrm{veg}} N_{\mathrm{veg}} u|\mathbf{V}|+c_{\mathrm{int}}(h u)_{t} \\
\tau_{y}^{\mathrm{veg}}=\frac{1}{2} \rho c_{\mathrm{d}} b_{\mathrm{veg}} h_{\mathrm{veg}} N_{\mathrm{veg}} v|\mathbf{V}|+c_{\mathrm{int}}(h v)_{t}
\end{gathered}
$$

where $b_{\text {veg }}$ is stem width normal to wave propagating direction, $h_{\text {veg }}$ stem height under water, $N_{\text {veg }}$ number of stems per unit area, $c_{\mathrm{d}}$ and $c_{\text {int }}$ are drag and inertia force coefficients, defined based on the ones proposed by Harada and Imamura (2005) and modified here for the best fit to laboratory measurements undertaken by Thuy et al. $(2009,2010)$ as

$$
\begin{array}{cc}
c_{\mathrm{d}}=0.10+0.8 V_{\mathrm{veg}} / V_{\mathrm{w}} & \left(0.01 \leq V_{\mathrm{veg}} / V_{\mathrm{w}} \leq 0.07\right) \\
c_{\text {int }}=c_{\mathrm{m}} \rho b_{\text {veg }} d_{\text {veg }} h_{\text {veg }} N_{\text {veg }} & \left(c_{\mathrm{m}}=0.15\right)
\end{array}
$$

where $d_{\text {veg }}$ is plant stem diameter, $V_{\text {veg }} / V_{\mathrm{w}}$ vegetation volume under water per unit water volume. 


\subsection{Numerical Scheme}

The integral form of the equations (1) and (2) is

$$
\frac{\partial}{\partial t} \int_{A} \mathbf{U}^{*} d A+\int_{S} \mathbf{F}^{*} \cdot \mathbf{n} d S=\int_{A} \mathbf{Q}_{S}^{*} \mathrm{~d} A
$$

where $\mathbf{U}^{*}, \mathbf{F}^{*}$ and $\mathbf{Q}_{s}^{*}$ defined as

$$
\begin{aligned}
& \mathbf{U}^{*}=\left(h,\left(1+\frac{1}{\rho} c_{\mathrm{int}}\right) h u,\left(1+\frac{1}{\rho} c_{\mathrm{int}}\right) h v\right)^{T} \\
& \mathbf{F}^{*}=\left(h \mathbf{V}, h u \mathbf{V}+\frac{1}{2} h^{2} \mathbf{i}, h v \mathbf{V}+\frac{1}{2} h^{2} \mathbf{j}\right)^{T} \\
& \mathbf{Q}_{s}^{*}=\left(\begin{array}{l}
0 \\
-g h \frac{\partial \eta}{\partial x} \\
-g h \frac{\partial \eta}{\partial y}
\end{array}\right)+\left(\begin{array}{l}
0 \\
-\frac{1}{\rho} \tau_{x}^{\mathrm{f}} \\
-\frac{1}{\rho} \tau_{y}^{\mathrm{f}}
\end{array}\right)+\left(\begin{array}{l}
0 \\
-\frac{1}{2} c_{\mathrm{d}} b_{\mathrm{veg}} h_{\mathrm{veg}} N_{\mathrm{veg}} u|\mathbf{V}| \\
-\frac{1}{2} c_{\mathrm{d}} b_{\mathrm{veg}} h_{\mathrm{veg}} N_{\mathrm{veg}} v|\mathbf{V}|
\end{array}\right)
\end{aligned}
$$

$A$ is the area enclosed by the control surface $S$.

Here, we apply the MUSCL-Hancock finite volume scheme with appropriate modifications for Cartesian cut cell meshes (Causon et al., 2000; 2001). This is a two-step, high resolution, upwind scheme of the Godunov type. Time integration is performed using a two-step predictor-corrector scheme. The MUSCL-Hancock scheme is second order accurate in both time and space in smooth regions. The predictor step uses a non-conservative approach, which defines an intermediate cell centre value over a time interval $\Delta t / 2$.

$$
\left(A \mathbf{U}^{*}\right)_{i, j}^{n+1 / 2}=\left(A \mathbf{U}^{*}\right)_{i, j}^{n}-\frac{\Delta t}{2} \sum_{k=1}^{m} F_{k}^{*} \cdot S_{k}-\left(A \mathbf{Q}_{s}^{*}\right)_{i, j}^{n}
$$

The corrector step of the scheme is fully conservative. The intermediate solution from the predictor step is used to define a set of left- and right-hand states for a series of Riemann problems. To solve the Riemann problem, the approximate Riemann solver of Harten, Lax and van Leer (HLL) is used. The detailed procedures can be found in the references Causon et al. (2000, 2001) and Zhou et al. (2001). 
At the seaward incident boundary, the incident periodic wave is given as a time-dependent boundary condition. For a periodic wave, the incident boundary condition should be able to prescribe an incoming wave and allow the reflected wave to exit the computational domain. Here, characteristic methods are used to achieve non-reflective wave generation at the incident boundary, and the Eq. (1) and (2) are reduced to the linear long-wave equations and expressed in characteristic form to prescribe the incoming wave while allowing reflected waves to exit the computational domain. The detailed procedures of characteristic methods for a periodic wave incident boundary condition can be found in the references Kobayashi et al. (1987) and Incelli et al. (2015).

\section{Numerical Model Validation}

The proposed model is firstly run for a solitary wave on a bare sloping beach to test the accuracy of the numerical scheme for modeling wave run-up. Then the model and solver are tested for a long period wave run-up on a vegetated sloping beach.

\subsection{Solitary Wave Run-up on a Bare Sloping Beach}

Synolakis (1987) carried out a series of experiments to investigate solitary wave run-up on a bare sloping beach, and the experimental results have been extensively used to validate wave run-up models. The topography consists of a plane beach with a 1: 19.85 slope adjacent to a constant depth region. The surface profile and velocity of the solitary wave can be defined by first-order solitary wave theory for an initial wave shape and velocity (Synolakis, 1987)

$$
\begin{aligned}
& \eta=H \operatorname{sech}^{2}\left(\sqrt{3 H / 4 h_{0}^{3}}\left(x-X_{1}\right)\right) \\
& u=c \eta /(1+\eta) \\
& c=\sqrt{g\left(H+h_{0}\right)}
\end{aligned}
$$

where $H$ is initial relative wave height of a solitary wave, $h_{0}$ water depth, $X_{1}$ position of initial wave crest in computing domain, $u$ velocity, and $c$ wave celerity. The present model is used to reproduce Synolakis' cases for a solitary wave running up the beach to examine the accuracy of the numerical scheme for predicting the 
detailed process of wave run-up. Experimental results are obtained from Synolakis (1987).

In the simulations, the numerical model is run on a uniform spatial grid with spatial resolution $\Delta x=0.01$. The value of the bed friction coefficient has been numerically investigated for the best fit to the laboratory measurements (Synolakis, 1987), and is determined to be 0.001 . Fig. 1 shows the computed free surface evolution of a solitary wave with $H / h_{0}=0.0185$ against the experimental results at different non-dimensional times $\mathrm{t}\left(\mathrm{g} / h_{0}\right)^{0.5}: 35,40,45,50,55,60,65,70$ as it runs up the sloping beach. As can be seen in Fig. 1 the solitary wave reaches maximum run-up at about $\mathrm{t}\left(\mathrm{g} / h_{0}\right)^{0.5}=50$ to $\mathrm{t}\left(\mathrm{g} / h_{0}\right)^{0.5}=55$, then back wash begins and the maximum run-down occurs at about $\mathrm{t}\left(\mathrm{g} / h_{0}\right)^{0.5}=65$ to $\mathrm{t}\left(\mathrm{g} / h_{0}\right)^{0.5}=70$. The numerically simulated solitary wave reaches the maximum run-up at $\mathrm{t}\left(\mathrm{g} / h_{0}\right)^{0.5}=$ 52.3 , and the maximum run-down occurs at $\mathrm{t}\left(\mathrm{g} / h_{0}\right)^{0.5}=69.6$. There is good agreement between the simulated and experimental results throughout the whole process. This indicates that the present model is well placed to predict the details of solitary wave run-up on a sloping beach.

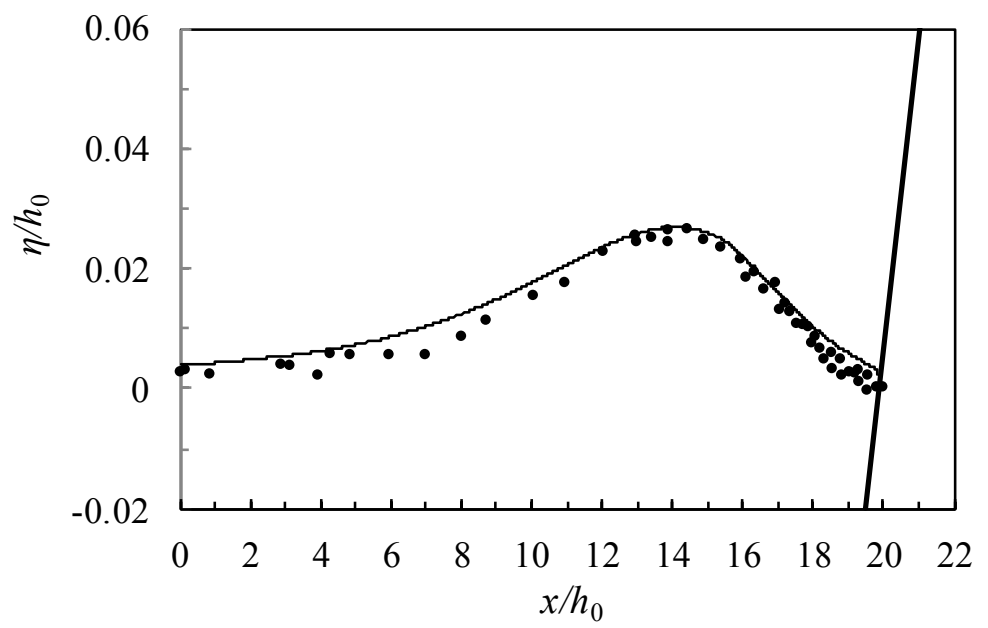

(a) 


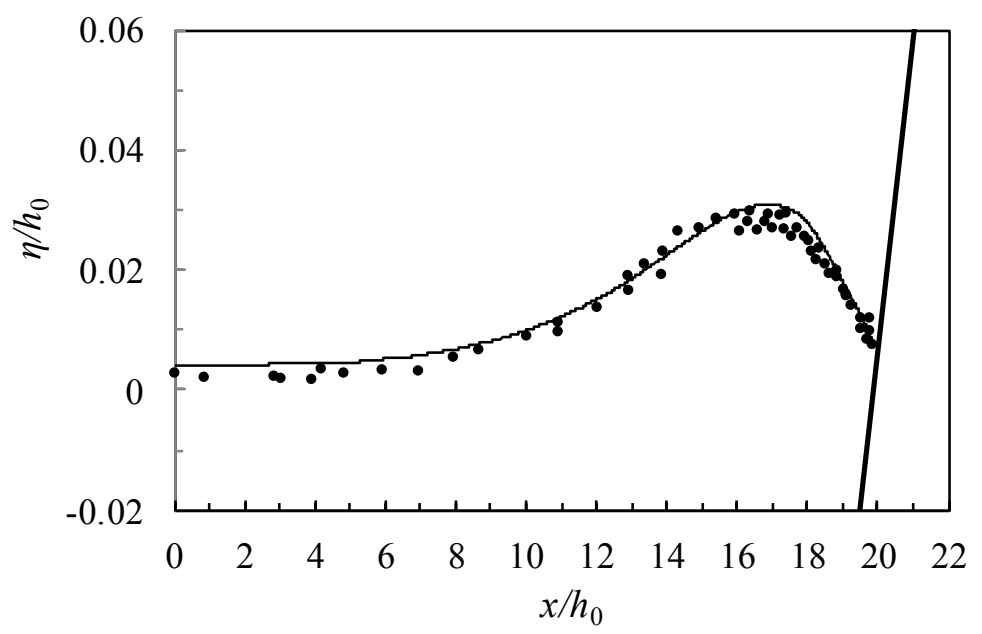

(b)

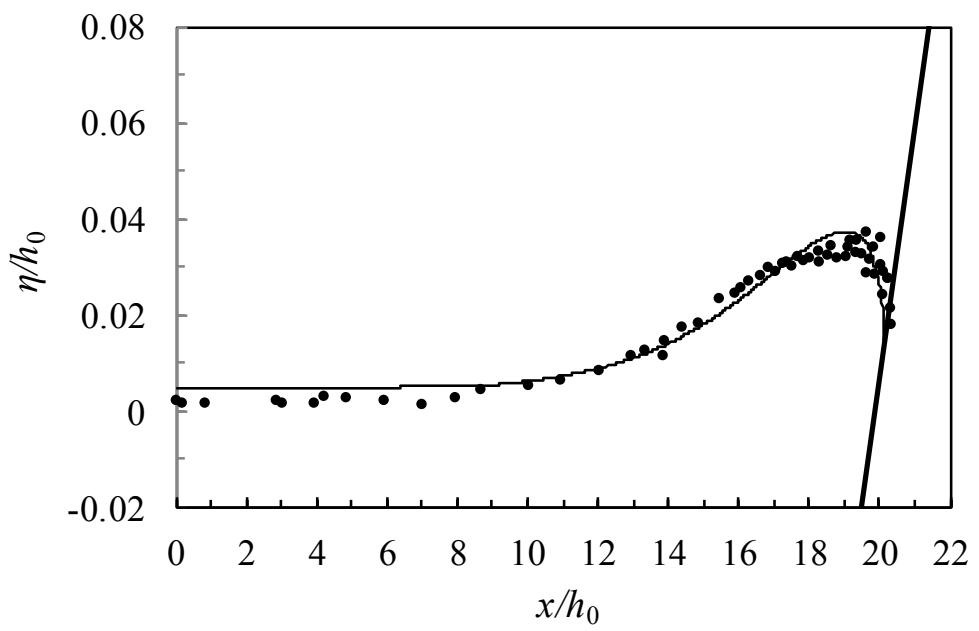

(c)

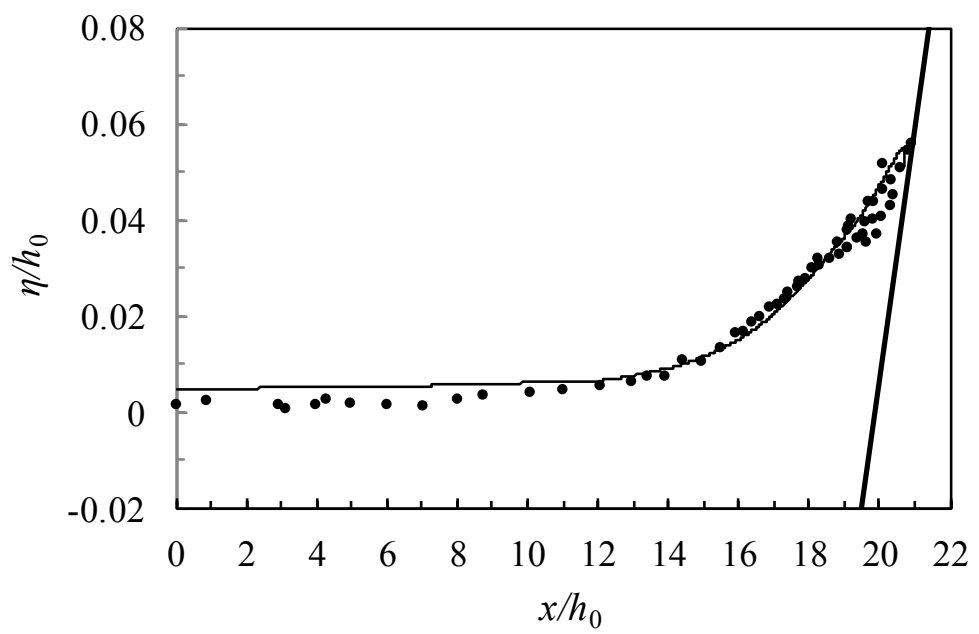

(d) 


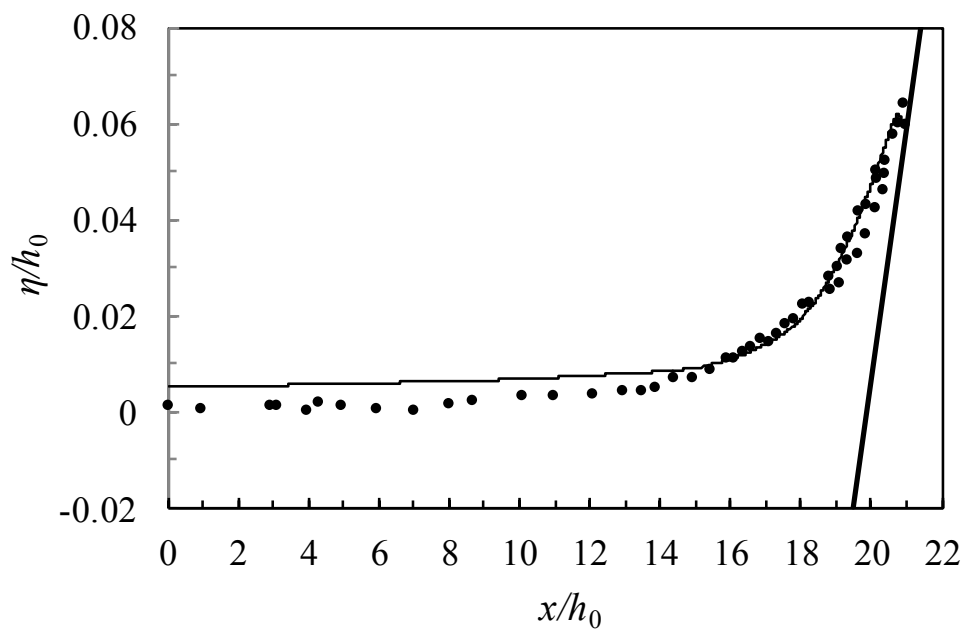

(e)

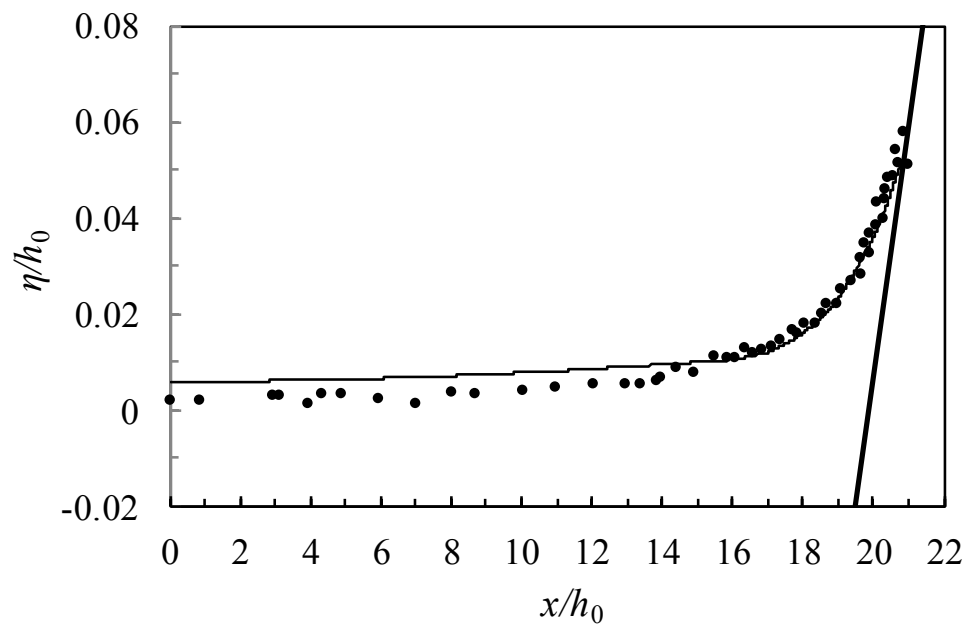

(f)

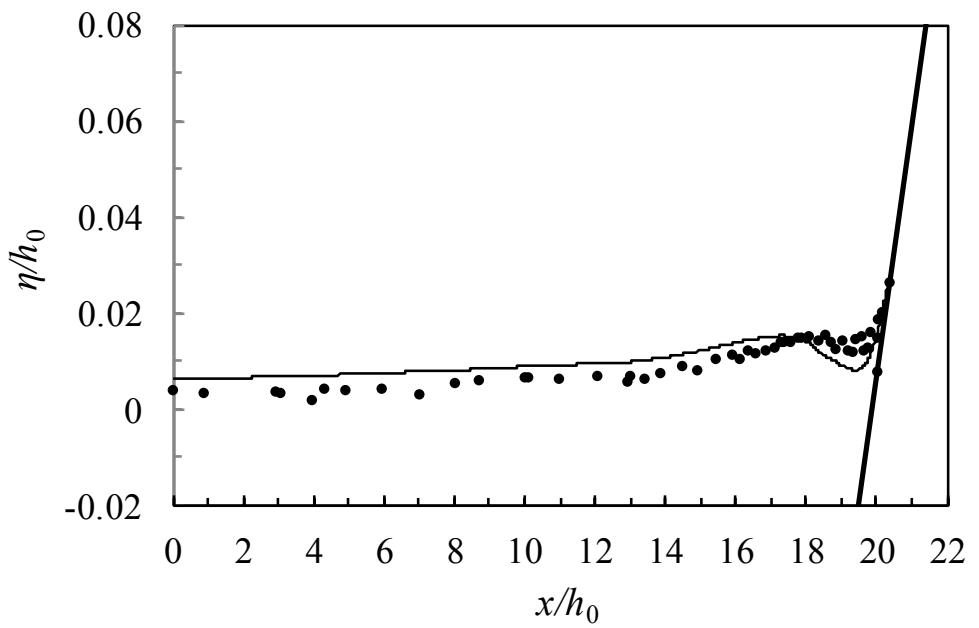

(g) 


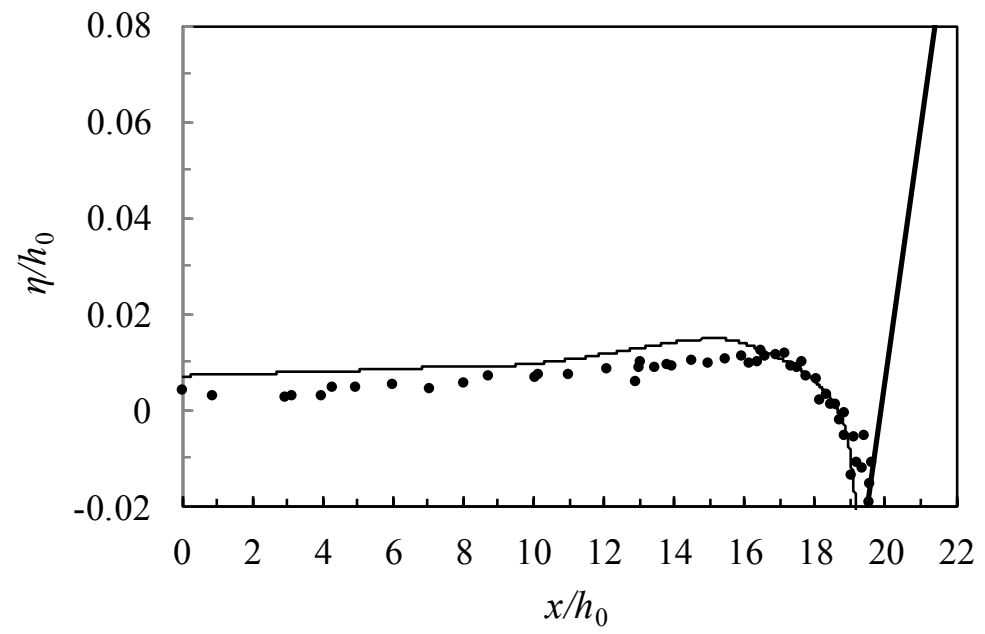

(h)

- Numerical Results

. . Laboratory data by Synolakis (1987)

Fig. 1 Run-up of a solitary wave with $H / h_{0}=0.0185$ on 1:19.85 bare sloping beach at different non-dimensional times $\mathrm{t}\left(\mathrm{g} / h_{0}\right)^{0.5}$ : (a) 35; (b) 40; (c) 45; (d) 50; (e) 55; (f) 60; (g) 65; (h) 70.

\subsection{Long Periodic Wave Run-up on a Partially Vegetated Sloping Beach}

Thuy et al. $(2009,2010)$ conducted a laboratory experiment of long wave run-up on a partially vegetated sloping beach. The experiment was conducted in a wave flume 15 $\mathrm{m}$ long and $0.4 \mathrm{~m}$ wide. The flume beach profile consisted of segments with various slopes, and the main slope was $1: 20.5$. The vegetation was fixed from $\mathrm{x}=10.36 \mathrm{~m}$ to $\mathrm{x}=11.36 \mathrm{~m}$ on bottom of the flume, and fully occupied the flume width. The vegetation was modelled by wooden cylinders with a diameter of $5 \mathrm{~mm}$ in a staggered arrangement, and the plant density is $2200 \mathrm{unit} / \mathrm{m}^{2}$. An incident sinusoidal wave with period $20 \mathrm{~s}$ and height $0.02 \mathrm{~m}$ was generated on the offshore side, and the still water depth was $0.44 \mathrm{~m}$.

The numerical model is run on a uniform spatial grid with a spatial step $\Delta x=0.01$. The value of the bed friction coefficient has been numerically investigated for the best fit to the laboratory measurements (Thuy et al., 2009; 2010), and is determined to be 0.01. Fig. 2 shows the computed wave height, crest and trough against the experimental results as the incident sinusoidal wave runs up a bare and vegetated sloping beach. As can be seen in Fig. 2, both the numerical results and experimental results show that the wave heights increase due to shoaling as the waves propagate to the shore. In the case of vegetation on the slope, however, the increase of wave height in the vegetated sloping zone is attenuated by vegetation, and the wave height at the front of the vegetation is affected by the waves reflected due to the vegetation. The 
maximum wave run-up and run-down are decreased in the case of vegetation compared with those in the case of no vegetation. There is good agreement over the whole range between the simulated and experimental results of Thuy et al. (2009, 2010) for wave height, crest and trough. The simulated wave height at the deepest gage also agrees fairly well with measured height, and this indicates that characteristic methods are effective for achieving non-reflective wave generation at the incident boundary in the present study. These results show that the present model is well able to predict long periodic wave propagation and run-up on a vegetated sloping beach.

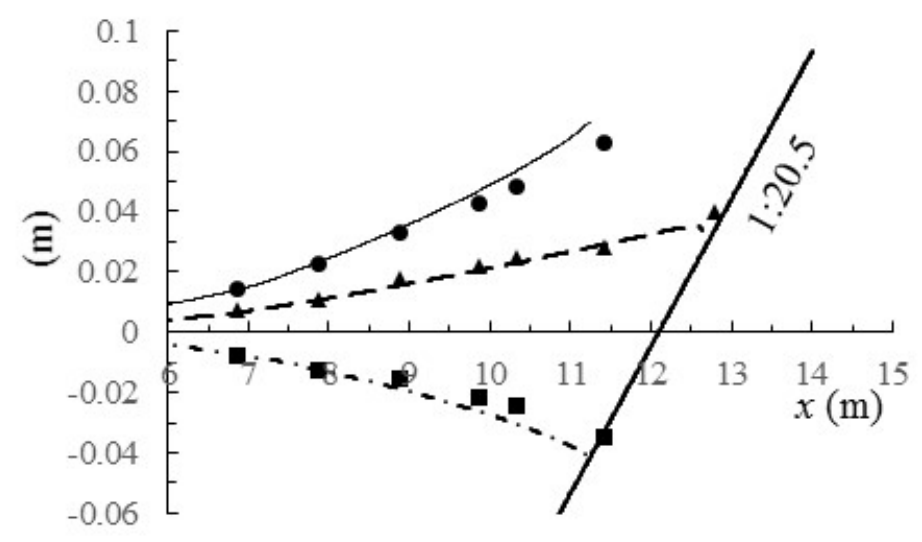

(a)

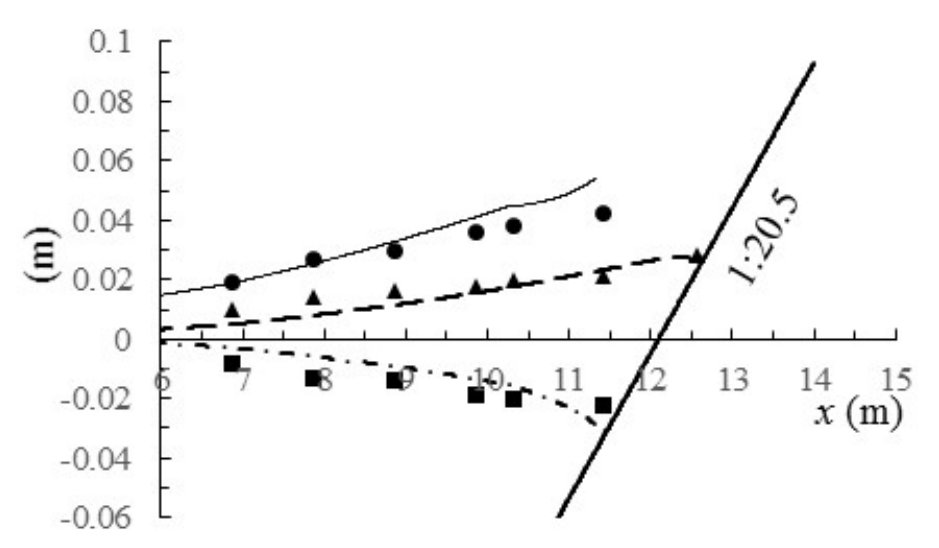

(b)

— Simulated wave height

- - S Simulated wave crest

-.-. Simulated wave trough
- - Measured wave height

$\Delta \Delta$ Measured wave crest

- Measured wave trough

Fig. 2 Comparison between numerical and experimental results (Thuy et al., 2009, 
2010) for wave height, wave crest and wave trough as the incident sinusoidal wave runs up the bare and partially-vegetated sloping beach: (a) wave run-up on a bare sloping beach; (b) wave run-up on a partially-vegetated sloping beach

\section{Numerical Experiments and Analysis}

Following validation of the present numerical model, numerical tests are performed to study the sensitivity of long periodic wave run-up on a vegetated sloping beach to plant diameter and density, as well as wave period. In the tests, a periodic wave with initial height $H / h_{0}=0.02$ propagating from a $2 \mathrm{~m}$ long constant bottom section of water depth $h_{0}=0.5 \mathrm{~m}$ to a 1:20 sloping beach was studied. Plants with a height of $1.0 \mathrm{~m}$ (above still water) are planted uniformly from $x=10.0 \mathrm{~m}$ to $x=12.0 \mathrm{~m}$ on the bottom of the beach, and fully occupied the beach width. The bed friction coefficient was set to be 0.001 . Figure 3 shows the profile of the numerical model set-up. The wave run-up value is defined as the maximum value of the water surface level at the moving shore line boundary recorded from the simulated time history of water surface level.

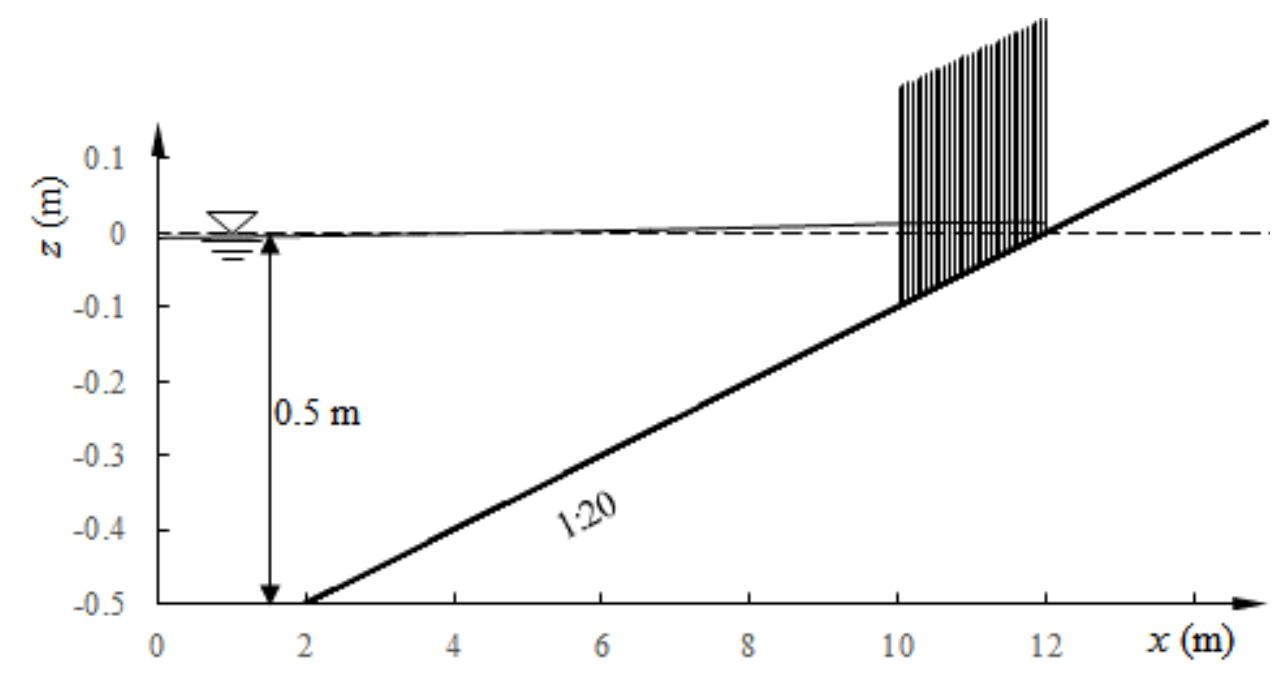

Fig. 3 Profile of the numerical model set-up

\subsection{Plant Diameter Effects on Long Periodic Wave Run-up}

In this test, the wave period for the incident waves is $20 \mathrm{~s}$ and plant density is set as $2000 \mathrm{unit} / \mathrm{m}^{2}$. Four different plant diameters of $0.005 \mathrm{~m}, 0.01 \mathrm{~m}, 0.015 \mathrm{~m}$ and $0.02 \mathrm{~m}$ 
have been used to examine its effects on wave run-up. The same set up is run on a sloping beach with and without vegetation.

Fig. 4 shows the simulated wave height and maximum wave run-up as the incident wave climbs up the bare and partially planted sloping beach with different plant diameter in the test cases. In fig. 4 (a), the plant diameter is $0.005 \mathrm{~m}$, and the wave height in the planted zone is obviously decreased compared to that on a bare slope, and the wave height offshore of the vegetation is also different from that offshore of the bare slope. Moreover, the maximum wave run-up on the vegetated slope is decreased by about $35 \%$ compared with that on the bare slope in fig. 4 (a). In fig. 4 (b), the plant diameter is $0.01 \mathrm{~m}$, and wave height in the planted zone is decreased more than that in fig. 4 (a). Meanwhile, the wave height evolution offshore of the vegetation is also affected by the vegetation and different from that in fig. 4 (a). Also, the maximum wave run-up on the vegetated slope is decreased by about $61 \%$ compared with that on the bare slope in fig. 4 (b). In fig. 4 (c), the plant diameter is $0.015 \mathrm{~m}$, and the wave height in the planted zone is decreased more obviously than that in the planted zone in fig. 4 (b), and the wave height evolution offshore of the vegetation is also obviously affected by vegetation. Meanwhile, the maximum wave run-up on the vegetated slope is decreased by about $76 \%$ compared with that on the bare slope in fig. 4 (c). In fig. 4 (d), the plant diameter is $0.02 \mathrm{~m}$, and the wave height on the planted zone is decreased more obviously than that in the planted zone in fig. 4 (c), and the wave height evolution offshore of the vegetation is also obviously affected by vegetation. Furthermore, the maximum wave run-up on the vegetated slope is decreased by about $87 \%$ compared with that on the bare slope in fig. 4 (d).

By comparing the numerical results for wave height on the bare and partially planted slopes with different plant diameters in fig. 4 , it can be seen that long wave height in the planted zone is attenuated and this attenuation increases with increasing plant diameter. Meanwhile, it is shown by comparison of the wave height evolution offshore of the planted zone in fig. 4, that this is different from that on the bare slope and also significantly different for cases with vegetation with different plant diameters. Moreover, It is also shown by comparison of wave run-up on a partially planted slope with different plant diameters in fig. 4 , that planting on the slope can decrease long wave run-up significantly, and attenuation of maximum wave run-up on a vegetated slope is increased with increase of plant diameter. This is similar to that found for a solitary wave passing through a vegetated slope (see Tang et al, 2013). These effects are because the drag forces due to vegetation are increased with increase of plant 
diameter, and hence, this results in a decrease of wave velocity and height on the planted zone with increase of plant diameter, and attenuation of wave run-up is also increased with increase of plant diameter. The high differences in wave height evolution offshore of the vegetation is due to the superposition of incident wave and reflected wave from the slope. Meanwhile, vegetation also has an effect on reflection of the incident wave, and results in phase difference between the incident and reflected waves due to vegetation that varies with vegetation diameters giving rise to variation in wave height evolution offshore of the planted zone.

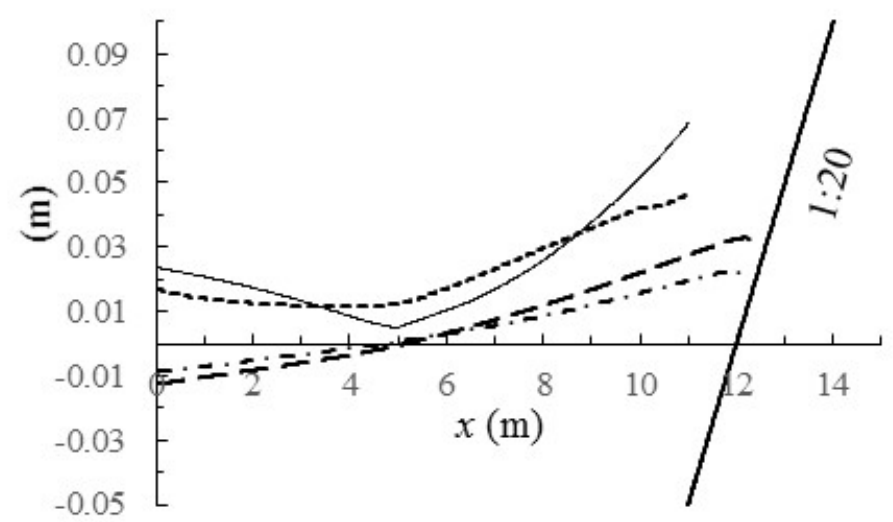

(a)

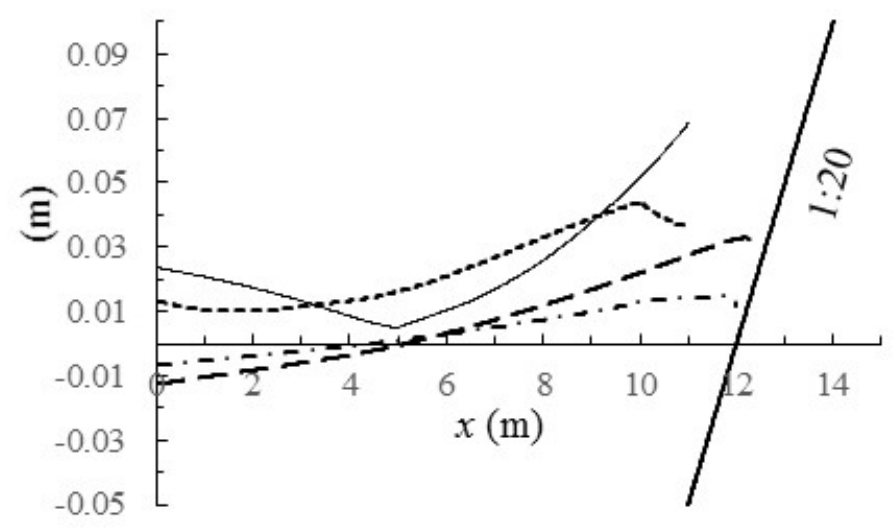

(b) 


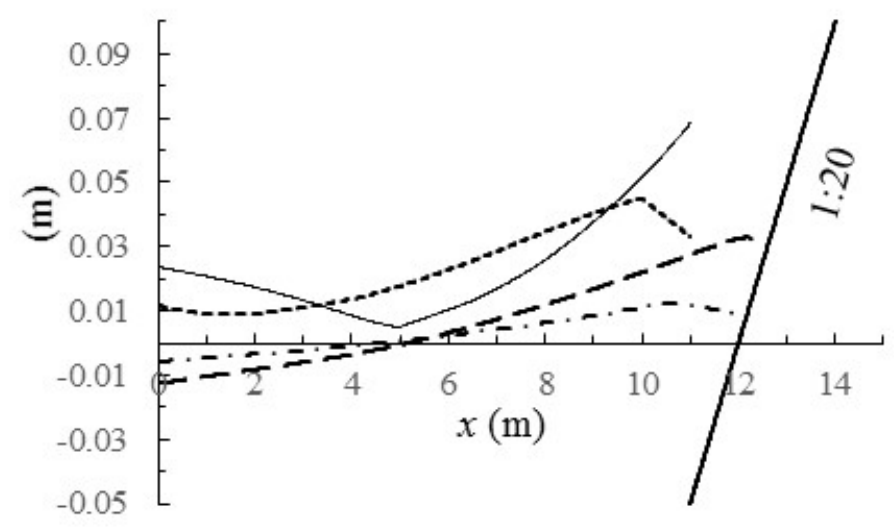

(c)

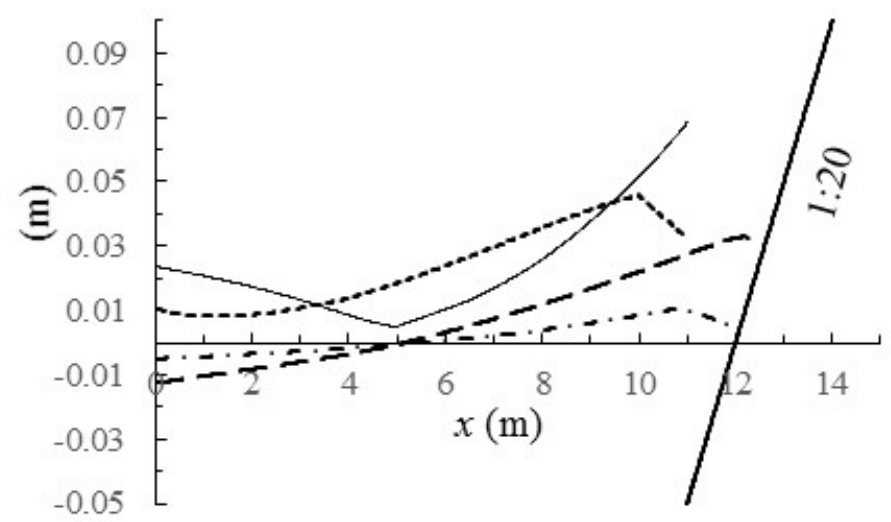

(d)

— Numerical results of wave height on bare sloping beach

- - Numerical results of maximum wave run-up on bare sloping beach
Numerical results of wave height on partial plant sloping beach

-. - Numerical results of maximum wave run-up on partial plant sloping beach

Fig. 4 Numerically simulated wave height and maximum wave run-up on a bare and partial planted sloping beach with diverse plant diameters: (a) plant with diameter $0.005 \mathrm{~m}$; (b) plant with diameter $0.01 \mathrm{~m}$; (c) plant with diameter $0.015 \mathrm{~m}$; (d) plant with diameter $0.02 \mathrm{~m}$.

\subsection{Plant Density Effects on Long Periodic Wave Run-up}

In this test, the period for the incident waves is again set as $20 \mathrm{~s}$. Plant diameter is fixed to $0.01 \mathrm{~m}$, but its density is set as $500 \mathrm{unit} / \mathrm{m}^{2}, 1000 \mathrm{unit} / \mathrm{m}^{2}, 1500 \mathrm{unit} / \mathrm{m}^{2}$ and 2000 unit $/ \mathrm{m}^{2}$ respectively. Fig. 5 shows the numerical simulated wave height and maximum wave run-up as the incident sinusoidal wave runs up the bare and partially planted sloping beach with diverse plant density. From the figure, it can be seen that 
for all cases, the wave height before vegetation has been affected by the vegetation and the wave height in the planted zone is reduced compared to that on a bare slope. The reduction in wave height in the planted zone increases with increase of plant density. The same trend can also be observed for the maximum wave run-up. For example, for the plant density of $500 \mathrm{unit} / \mathrm{m}^{2}$, the maximum wave run-up on the vegetation slope is reduced by about $19 \%$ compared with that on the bare slope in fig. 5 (a). By increasing the plant density to $1000 \mathrm{unit} / \mathrm{m}^{2}$, the maximum wave run-up on the vegetated slope is reduced by about $37 \%$ compared with that on the bare slope in fig. 5 (b). Fig. 5 (c) and (d) show the results for the plant density of 1500 unit $/ \mathrm{m}^{2}$ and $2000 \mathrm{unit} / \mathrm{m}^{2}$, from which it can be calculated that the maximum wave run-up on the vegetated slope has been reduced by $51 \%$ and $61 \%$ respectively compared with that on the bare slope.

By comparing the numerical results for wave height on the bare and partially planted slopes with different plant densities in fig. 5, it can be seen that the long wave height in the planted zone is obviously attenuated and the attenuation of wave height in the planted zone is increased with increase of plant density, and the wave height offshore of the planted zone is changed compared with that on the bare slope and is also different for vegetation with different plant densities. Moreover, it is shown by comparison of the wave run-up on a partially planted slope with different plant densities in fig. 5, that planting on the slope can significantly decrease long wave run-up, and the attenuation of maximum wave run-up on vegetated slopes also is increased with increase of plant density. This is similar to that found for a solitary wave passing through a vegetated slope (see Limura and Tanaka, 2012; Tang et al, 2013). These results are explained by the fact that the drag forces due to vegetation will increase with increase of plant density. Meanwhile, the resulting phase difference between incident and reflected waves also varies with plant density giving different wave heights offshore of the planted zone. 


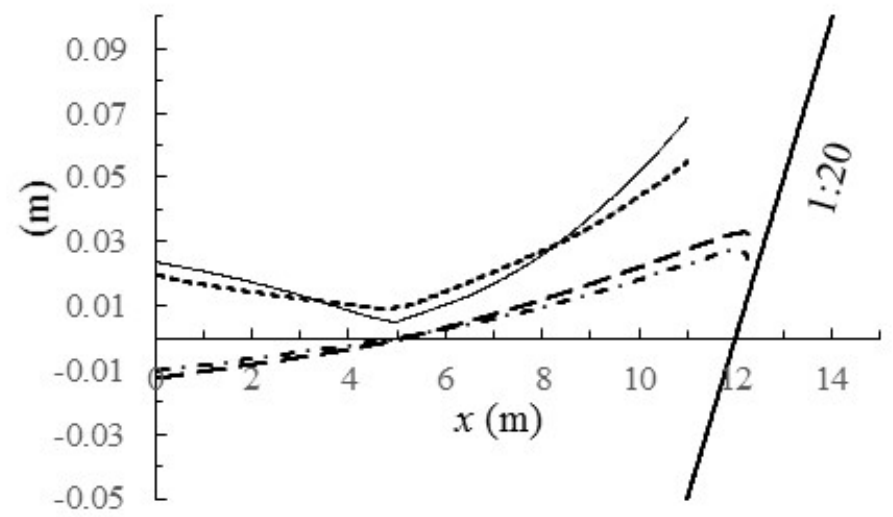

(a)

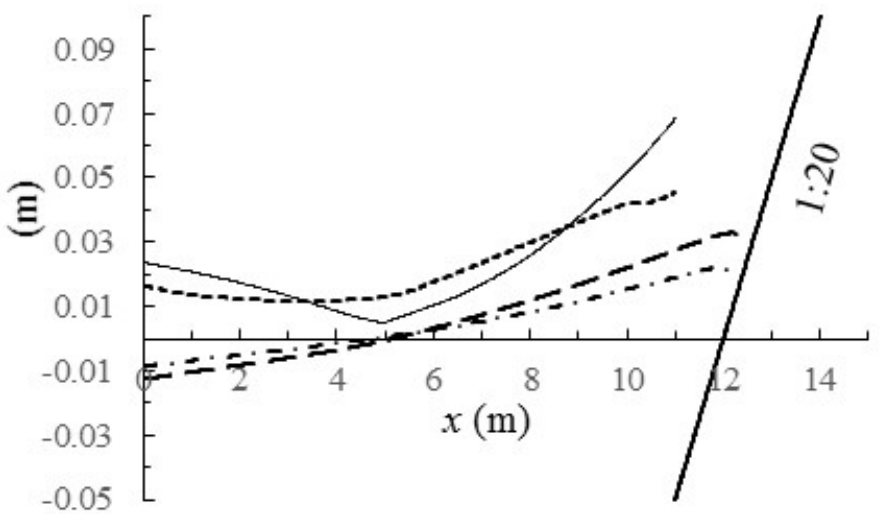

(b)

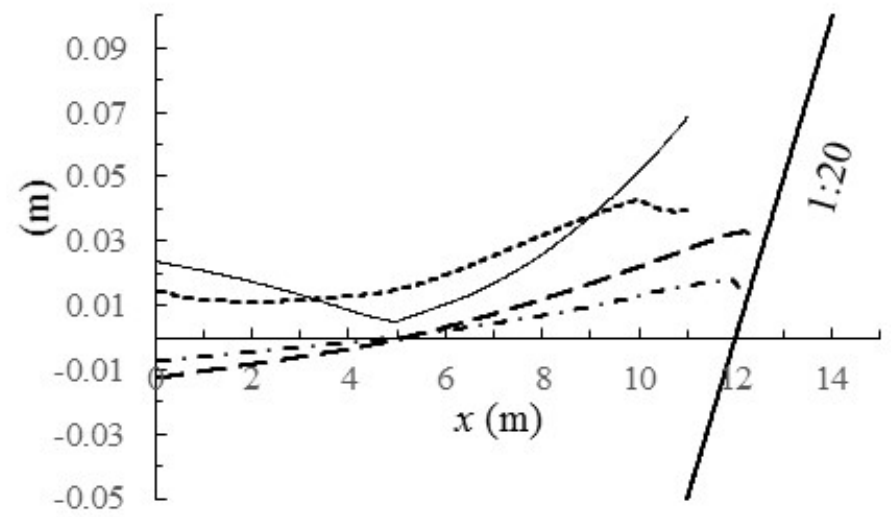

(c) 


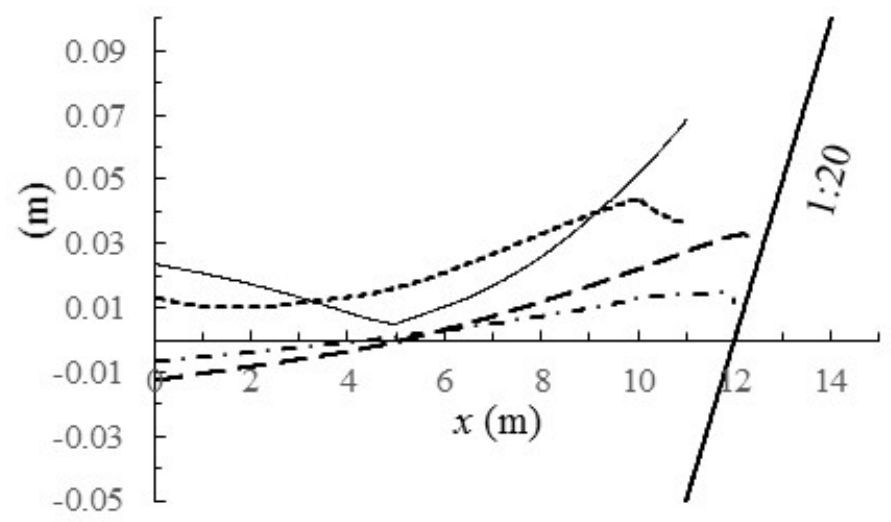

(d)

- Numerical results of wave height on bare slope

- - Numerical results of wave maximum run-up on bare slope

......... Numerical results of wave height on partial plant slope

-.- Numerical results of wave run-up maximum on partial plant slope

Fig. 5 Numerically simulated wave height and maximum wave run-up on a bare and partial planted sloping beach with diverse plant density: (a) plant with density 500 unit $/ \mathrm{m}^{2}$; (b) plant with density 1000 unit $/ \mathrm{m}$; (c) plant with density 1500 unit $/ \mathrm{m}$; (d) plant with density 2000 unit/m.

\subsection{Wave Period Effects on Long Periodic Wave Run-up}

In these tests, a periodic wave with initial height $H / h_{0}=0.02$ and diverse period $(7.5$ s, $10 \mathrm{~s}, 15 \mathrm{~s}, 20 \mathrm{~s}, 25 \mathrm{~s}, 30 \mathrm{~s}$ respectively) is set as the incident wave propagating towards the partially planted sloping beach. Plant diameter and density are set as 0.01 $\mathrm{m}$ and $2000 \mathrm{unit} / \mathrm{m}^{2}$ respectively. The same set up is run with and without vegetation on a sloping beach.

Fig. 6 shows the numerical simulated wave height and maximum wave run-up as an incident wave with different periods runs up the bare and partial vegetated sloping beach and in table 1, a detailed comparison of the maximum wave run-up and its reduction due to vegetation for all the wave periods considered is given. By comparing the simulated results in fig. 6 and in table 1 it can be seen that the wave height on the planted zone and the run-up of a long wave with diverse period are decreased significantly due to vegetation on the slope. Moreover, the attenuation rate of maximum wave run-up on a vegetated slope is increased from $60 \%$ to $86 \%$ as the incident wave period increased from $7.5 \mathrm{~s}$ to $10.0 \mathrm{~s}$, and then decreased to $41 \%$ as incident long wave period increased to $30 \mathrm{~s}$. These results suggest that the attenuation 
of long periodic wave run-up due to vegetation is sensitive to the variation of incident wave period, and the attenuation of maximum wave run-up is not increased or decreased monotonically with incident wave period. This is because the forces due to vegetation are not increased or decreased monotonically with incident wave period, which is similar to that found for a linear wave passing through a vegetated zone (see Tang et al, 2011). Moreover, it is also shown by comparison of wave height evolution offshore of a planted zone for a long wave with different periods in fig. 6, that the wave height evolution offshore of the planted zone is significantly different for long waves with different periods. This is because wave reflection is quite different for long waves with different periods, and the phase differences between the incident wave and reflected wave are also different. Hence, the superposition of incident wave and reflected wave from the slope result in a significant variance in wave height evolution.

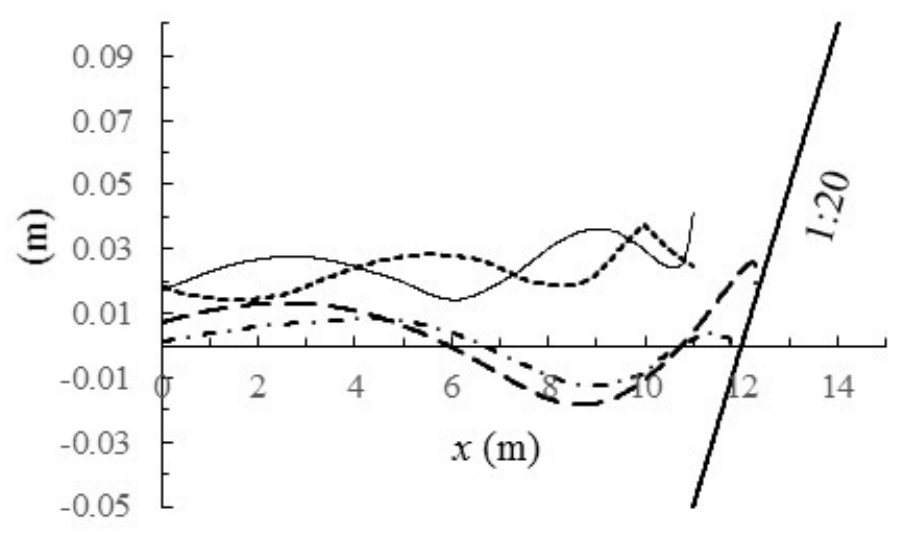

(a)

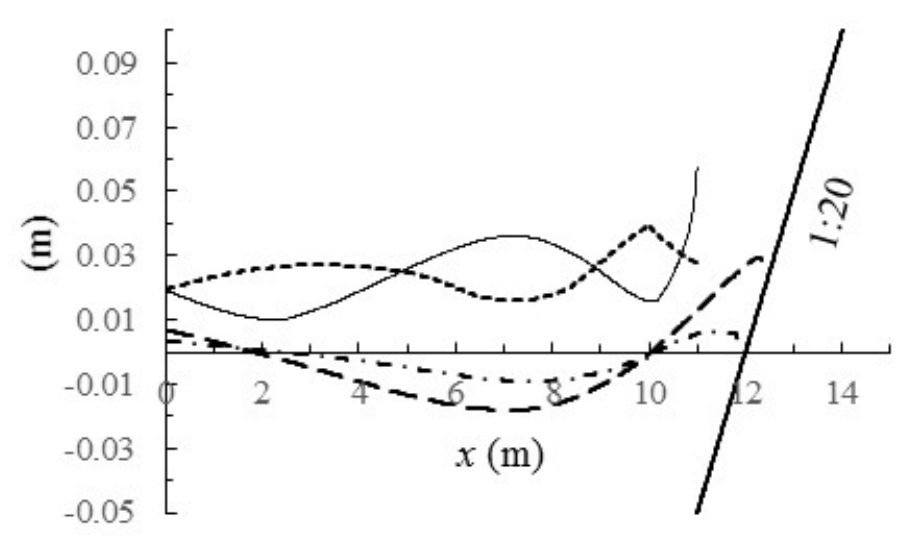

(b) 


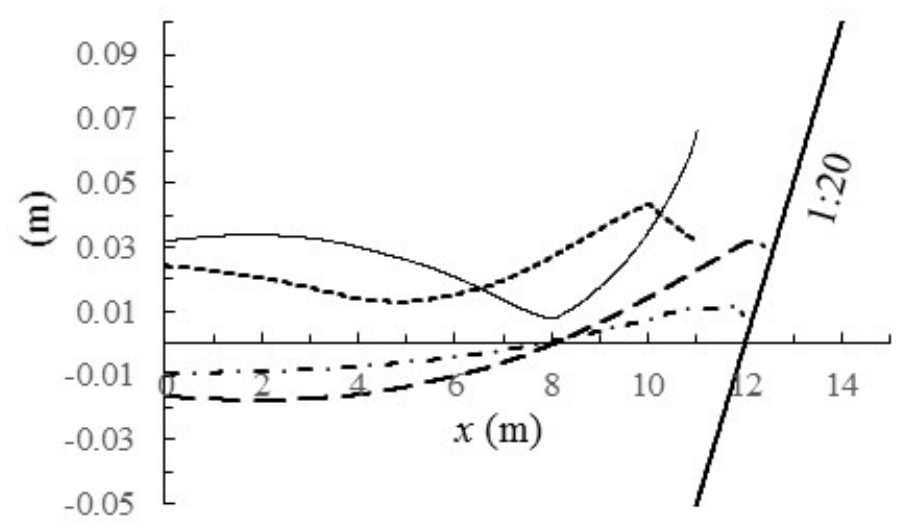

(c)

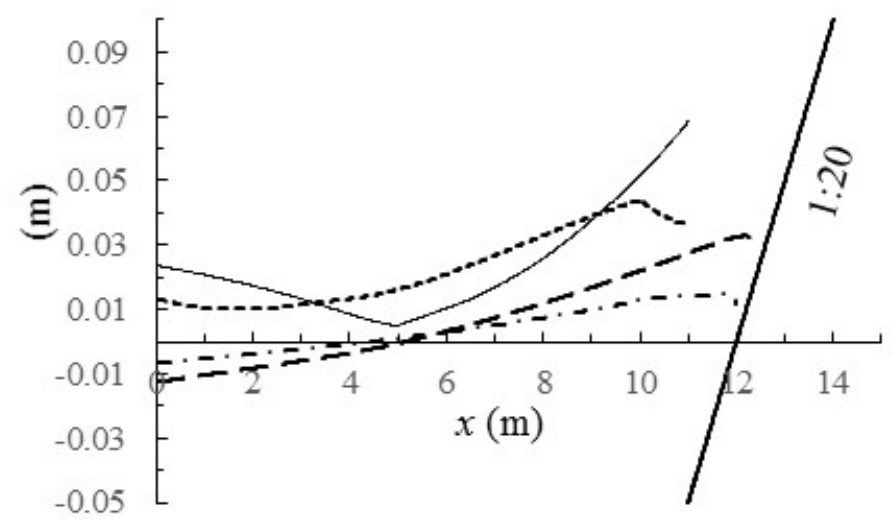

(d)

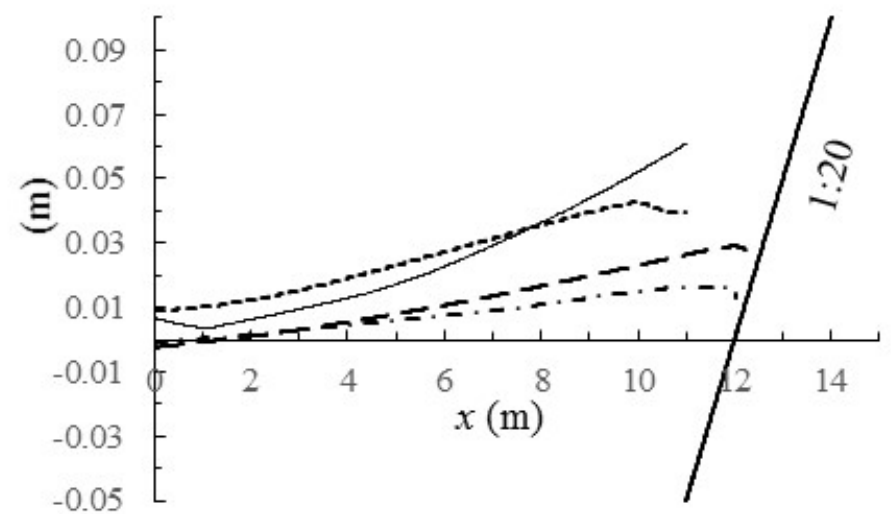

(e) 


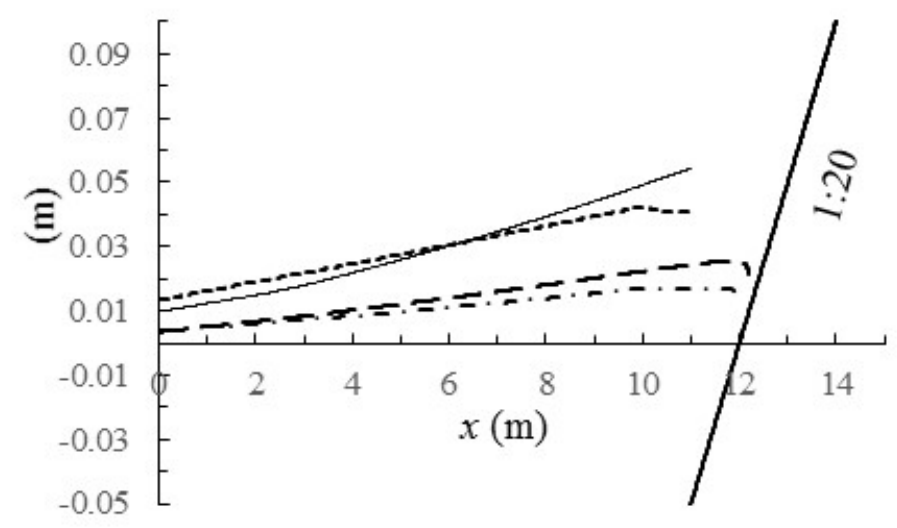

(f)

— Numerical results of wave height on bare slope

- - Numerical results of wave maximum run-up on bare slope
Numerical results of wave height on partial plant slope

-.- Numerical results of wave run-up maximum on partial plant slope

Fig. 6 Numerically simulated wave height and maximum run-up for an incident long wave with diverse period climbing up a bare and partially planted sloping beach: (a) long wave with period $7.5 \mathrm{~s}$; (b) long wave with period $10 \mathrm{~s}$; (c) long wave with period $15 \mathrm{~s}$; (d) long wave with period $20 \mathrm{~s}$; (e) long wave with period $25 \mathrm{~s}$; (f) long wave with period $30 \mathrm{~s}$.

Table 1 Comparison of the predicted maximum wave run-up and its reduction due to vegetation for different wave periods.

\begin{tabular}{|l|l|l|l|l|l|l|}
\hline Wave period (s) & 7.5 & 10 & 15 & 20 & 25 & 30 \\
\hline Wave run-up on bare slope (m) & 0.02 & 0.028 & 0.03 & 0.03 & 0.026 & 0.022 \\
\hline Wave run-up on planted slope (m) & 0.008 & 0.004 & 0.009 & 0.012 & 0.013 & 0.013 \\
\hline Reduction in wave run-up (\%) & 60 & 86 & 70 & 60 & 50 & 41 \\
\hline
\end{tabular}

\section{Conclusions}


The damping effects due to rigid vegetation on long wave run-up have been investigated numerically. In the simulations, rigid vegetation is approximated as rigid sticks, and the numerical model is based on an implementation of Morison's formulation (1950) for rigid structures with induced inertia and drag stresses in the nonlinear shallow water equations. The model was implemented via a finite volume approach and Cartesian cut cell meshes. The model was firstly validated by modeling a solitary wave run-up on a bare sloping beach and a long period wave run-up on a partially vegetated sloping beach, and good agreement was obtained between the numerical results and published experimental results. The model was then used to investigate the effects of vegetation damping by simulating various hypothetical cases of long period wave run-up on a vegetated sloping beach with different plant diameters, densities and for incident long waves with different periods. The numerical results show that vegetation can decrease long wave height and run-up significantly, and the attenuation rates on wave height in the planted zone and maximum wave run-up on vegetated slopes increase with increase of rigid plant diameter and stem density. Moreover, the wave height evolution offshore of the planted zone is also obviously different for vegetation with different plant diameters and densities as well as for incident long waves with different periods. Furthermore, the attenuation of long periodic wave run-up due to vegetation is sensitive to the variation of incident wave period, and the attenuation of wave run-up is not increased or decreased monotonically with increase of incident wave period.

It should be noted that in the present study, vegetation is represented by rigid sticks, which is obviously a simplification compared to real vegetation. Natural vegetation will be more complicated due to plant branches, leaves and their obvious non-rigidity, as well as spatial or seasonal variation in properties (Van Rooijen et al., 2016). In addition, due to a lack of available data, the results for long periodic wave run-up on planted sloping beaches have not been further validated against real vegetation data from laboratory tests or field measurements. In conclusion, the present study indicates that the model can simulate the essential flow processes of long periodic wave run-up on a vegetated slope, which can be used to qualitatively examine the effects of rigid vegetation on long periodic wave run-up. In future work, laboratory data using real vegetation or field data may be used to further validate our model and confirm the validity of our findings under naturally vegetated coastal environments.

\section{Acknowledgments}


The authors would like to acknowledge support from the National Natural Science Foundation of China under contract Nos 51579036 and 51579030, the Fundamental Research Funds for the Central Universities of China under Grant No. DUT14YQ10. Support from Centre for Mathematical Modelling and Flow Analysis at Manchester Metropolitan University is also gratefully acknowledged.

\section{References}

[1] Augustin L.N., Irish J.L, Lynett P., 2009. Laboratory and numerical studies of wave damping by emergent and near-emergent wetland vegetation. Coastal Engineering 56, 332-340

[2] Causon D.M., Ingram D.M., Mingham C.G., 2001. A Cartesian cut cell method for shallow water flows with moving boundaries. Advances in Water Resources 24, 899-911

[3] Causon D.M., Ingram D.M., Mingham C.G., Yang G., Pearson R.V., 2000. Calculation of shallow water flows using a Cartesian cut cell approach. Advances in Water Resources 23, 545-562

[4] Chen Q. and Zhao H.H., 2012. Theoretical models for wave energy dissipation caused by vegetation. Journal of Engineering Mechanics 138, 2: 221-229

[5] Fang K.Z., Liu Z.B., Zou Z.L., 2015. Efficient computation of coastal waves using a depth-integrated, non-hydrostatic model. Coastal Engineering 97, 21-36.

[6] Guannel G., Ruggiero P., Faries J., et al., 2015. Integrated modeling framework to quantify the coastal protection services supplied by vegetation. J. Geophys. Res. Oceans 120, 324-345, doi:10.1002/2014JC009821

[7] Harada K., Imamura F., 2005. Effects of coastal forest on tsunami hazard mitigation-a preliminary investigation. Advances in Natural and Technological Hazards Research 23, 279-292

[8] Huang Z.H., Yao Y., Sim S.Y., Yao Y., 2011. Interaction of solitary waves with emergent, rigid vegetation. Ocean Engineering 38, 1080-1088

[9] Iimura K., Tanaka N., 2012. Numerical simulation estimating effects of tree density distribution in coastal forest on tsunami mitigation. Ocean Engineering 54, $223-232$

[10]Incelli G., Briganti R., Dodd N., 2015. Absorbing-generating seaward boundary conditions for fully-coupled hydro-morphodynamical solvers. Coastal Engineering 99, 96-108

[11]Jadhav R.S., Chen Q., Smith J.M., 2013. Spectral distribution of wave energy dissipation by salt marsh vegetation. Coastal Engineering 77, 99-107

[12]Jiang C.B., Yao Y., Deng, Y., et al., 2015. Numerical Investigation of Solitary Wave Interaction with a Row of Vertical Slotted Piles. Journal of Coastal Research 31, 6: 1502-1511 
[13]Kobayashi N., Otta A. K., and Roy I., 1987. Wave reflection and run-up on rough slopes. Journal of Waterway, Port, Coastal, and Ocean Engineering 113, 3: 282-298

[14]Kobayashi N., Raichle A.W., Asano T., 1993. Wave attenuation by vegetation. Journal of Waterway, Port, Coast and Ocean Engineering 119, 30-48

[15]Liu P.L.F., Chang C.W., Mei C.C., et al., 2015. Periodic water waves through an aquatic forest. Coastal Engineering 96, 100-117

[16]Losada I.J., Maza M., Lara J.L., 2016. A new formulation for vegetation-induced damping under combined waves and currents. Coastal Engineering 107, 1-13

[17]Ma G., Kirby J.T., Su S.F., et al., 2013. Numerical study of turbulence and wave damping induced by vegetation canopies. Coastal Engineering 80, 68-78

[18] Maza M., Lara J.L., Losada I.J., 2013. A coupled model of submerged vegetation under oscillatory flow using Navier-Stokes equations. Coastal Engineering 80, 16-34

[19]Maza M., Lara J.L., Losada I.J., 2015. Tsunami wave interaction with mangrove forests: A 3-D numerical approach. Coastal Engineering 98, 33-54

[20]Mei C.C., Chan I.C., Liu P.L.F, et al., 2011. Long waves through emergent coastal vegetation. Journal of Fluid Mechanics 687, 461-491

[21]Morison J. R., O'Brien M.P., Johnson J.W., Schaaf S.A., 1950. The force exerted by surface waves on piles. Journal of Petroleum Technology 2, 149-154

[22]Phan L.K., van Thiel de Vries J.S.M., Stive M.J.F., 2015. Coastal Mangrove Squeeze in the Mekong Delta. Journal of Coastal Research 31, 2: 233-243

[23] Suzuki T., Zijlema M., Burger B., et al., 2012. Wave dissipation by vegetation with layer schematization in SWAN. Coastal Engineering 59, 64-71

[24] Synolakis C.E., 1987. The run up of solitary waves. Journal of Fluid Mechanics $185,523-545$

[25] Tanaka N., 2009. Vegetation bioshields for tsunami mitigation: review of effectiveness, limitations, construction, and sustainable management. Landscape and Ecological Engineering 5, 71-79

[26]Tang J., Causon D., Mingham C. and Qian L., 2013. Numerical study of vegetation damping effects on solitary wave run-up using the nonlinear shallow water equations. Coastal Engineering 75, 21-28

[27]Tang J., Shen S.D., Wang H., 2015. Numerical model for coastal wave propagation through mild slope zone in the presence of rigid vegetation. Coastal Engineering 97, 53-59

[28]Tang J., Shen Y.M., Cui L., 2011. Modeling coastal water wave propagation in vegetation field based on parabolic mild slope equation. Acta Oceanol. Sin. 33, 7-11 (in Chinese).

[29] Thuy N.B., Tanimoto K., Tanaka N., 2010. Flow and potential force due to runup tsunami around a coastal forest with a gap, experiments and numerical simulations. Sci. Tsunami Hazards 29, 2: 43-69 
[30] Thuy N.B., Tanimoto K., Tanaka, N., et al., 2009. Effect of open gap in coastal forest on tsunami run-up - Investigations by experiment and numerical simulation. Ocean Engineering 36, 1258-1269

[31]Van Rooijen A.A., McCall R.T., van Thiel de Vries J.S.M., et al., 2016. Modeling the effect of wave-vegetation interaction on wave setup. J. Geophys. Res. Oceans 121, doi:10.1002/2015JC011392

[32]Wang B. L., Guo X. Y., Mei C. C., 2015. Surface water waves over a shallow canopy. Journal of Fluid Mechanics 768, 572-599

[33] Wu W. and Marsooli R., 2012. A depth-averaged 2-D shallow water model for breaking and non-breaking long waves affected by rigid vegetation. Journal of Hydraulic Research IAHR 50, 6: 558-575

[34]Zhang M.L, Hao Z.N., Zhang Y.P., 2013. Numerical simulation of solitary and random wave propagation through vegetation based on VOF method. Acta Oceanologica Sinica 32, 7: 38-46

[35]Zhou J.G., Causon D.M., Mingham C.G., Ingram D.M., 2001. The surface gradient method for the treatment of source terms in the shallow-water equations. Journal of Computational Physics 168, 1-25

[36]Zhu L., Chen Q., 2015. Numerical modeling of surface waves over submerged flexible vegetation. Journal of Engineering Mechanics 141, 8: A4015001

[37]Zijlema M., Stelling G.S., 2008. Efficient computation of surf zone waves using the nonlinear shallow water equations with non-hydrostatic pressure. Coastal Engineering 47, 1-26 